06

\title{
Связь ликвации с температурой Дебая
}

\author{
() В.Я. Хентов, ${ }^{1}$ Е.Ю. Шачнева, ${ }^{2}$ В.В. Семченко ${ }^{1}$
}

${ }^{1}$ Южно-Российский государственный политехнический университет, 346428 Новочеркасск, Россия

${ }^{2}$ Астраханский государственный университет, 414000 Астрахань, Россия

e-mail: vkhentov@mail.ru; evgshachneva@yandex.ru

(Поступило в Редакцию 12 февраля 2018 г.)

Установлено, что ряд параметров, характеризующих процесс ликвации, связан с характеристической температурой Дебая химического элемента. Коэффициенты корреляции всегда превышали значение 0.9 .

DOI: $10.21883 /$ JTF.2019.04.47314.63-18

Под ликвацией понимают неоднородность химического состава, возникающую при кристаллизации расплава. Различают ликвацию в пределах слитка - зональную

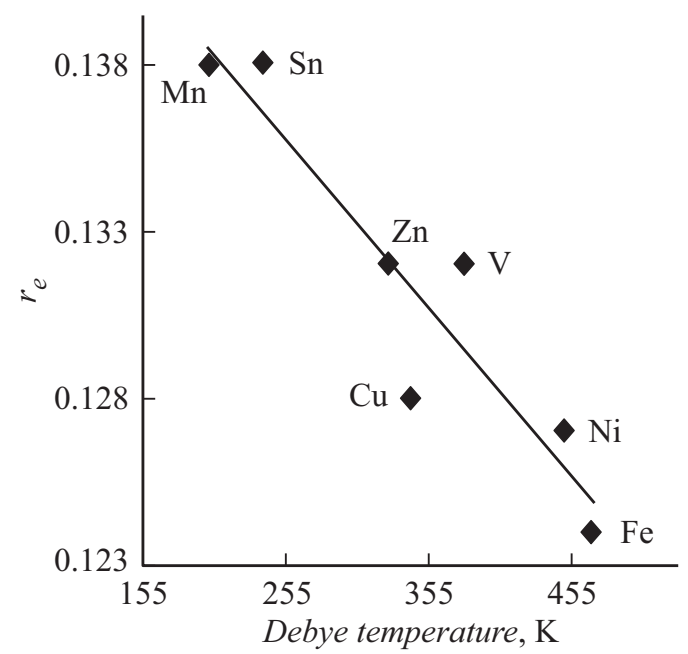

Рис. 1. Зависимость значений эффективного атомного радиуca $r_{e}$.

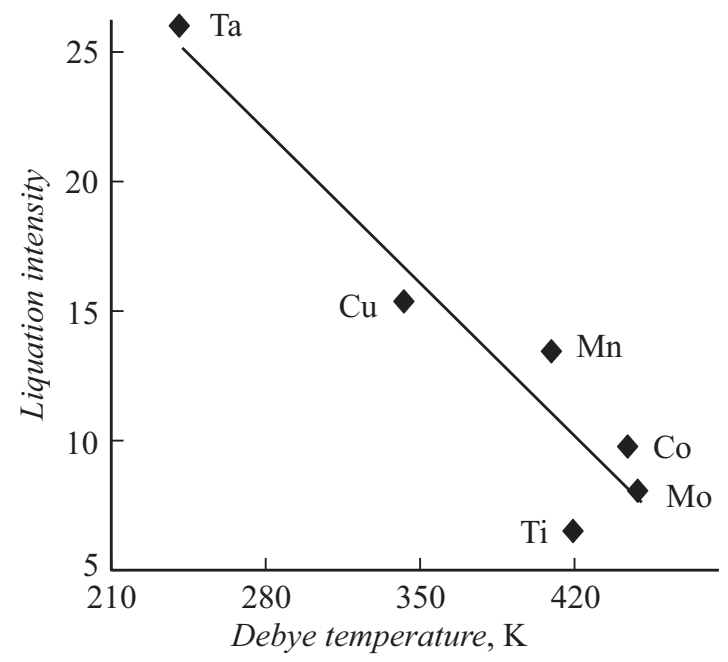

Рис. 2. Зависимость интенсивности ликвации от температуры Дебая. Коэффициент корреляции 0.949. (макроскопический уровень) или в пределах дендрита дендритную (микроскопический уровень). Можно показать, что различные параметры, связанные с ликвацией,

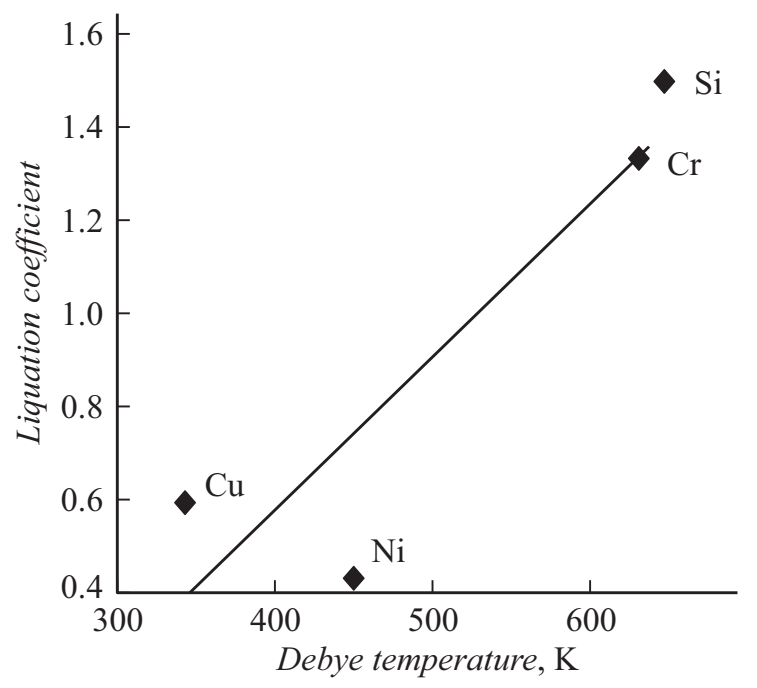

Рис. 3. Зависимость коэффициента ликвации от температуры Дебая. Коэффициент корреляции 0.906.

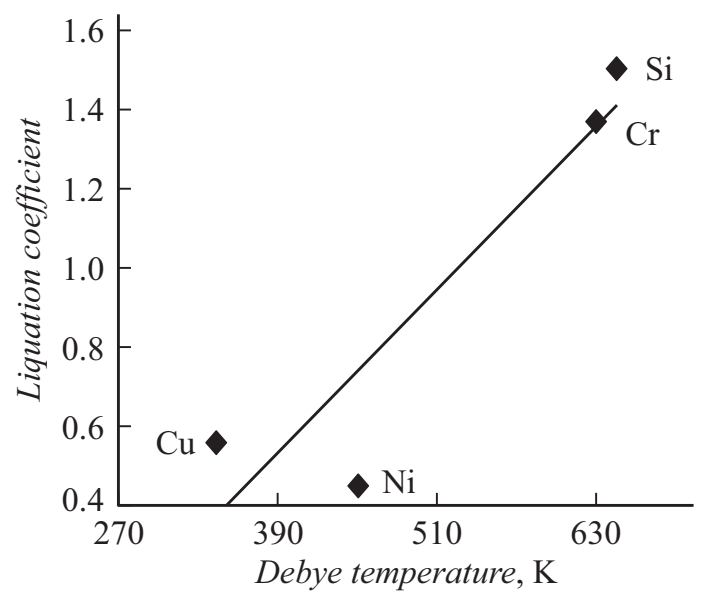

Рис. 4. Зависимость коэффициента ликвации от температуры Дебая. Коэффициент корреляции 0.924. 
Влияние способа закалки на распределение элементов $(C)$ в междендритных микрообъемах, коэффициент корреляции $R$

\begin{tabular}{l|c|c}
\hline Содержание элементов $C(\%)$ & $R$ & Условия закалки \\
\hline$C=-2.3118+0.0074 \Theta$ & 0.994 & Исходное литое состояние \\
$C=-2.0785+0.0078 \Theta$ & 0.881 & Закалка в охлажденной воде $1150^{\circ} \mathrm{C}$ в течение $10 \mathrm{~h}$ \\
$C=-2.0785+0.0078 \Theta$ & 0.880 & Закалка в охлажденной воде $1150^{\circ} \mathrm{C}$ в течение $10 \mathrm{~h} ;$ отпуск $700^{\circ} \mathrm{C}, 2 \mathrm{~h}$
\end{tabular}

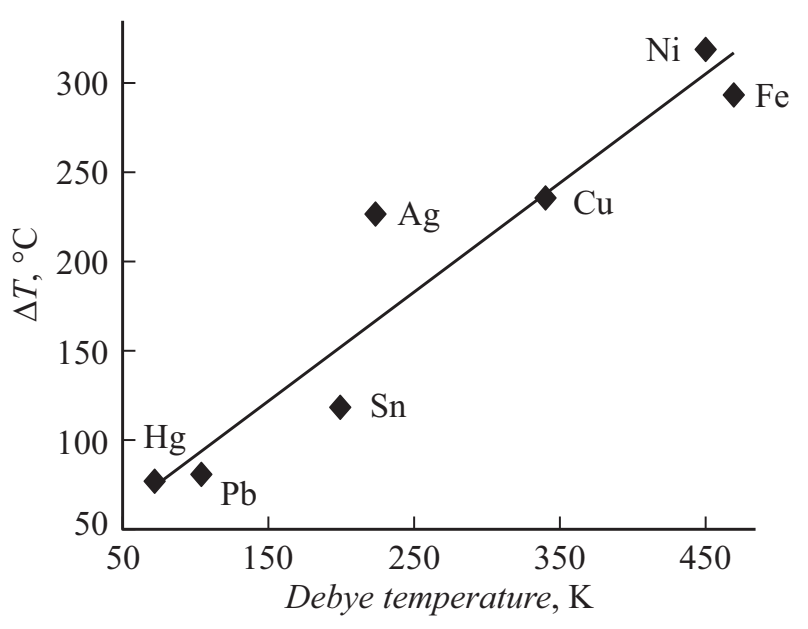

Рис. 5. Зависимость максимального переохлаждения $\Delta T$ от температуры Дебая. Коэффициент корреляции 0.953.

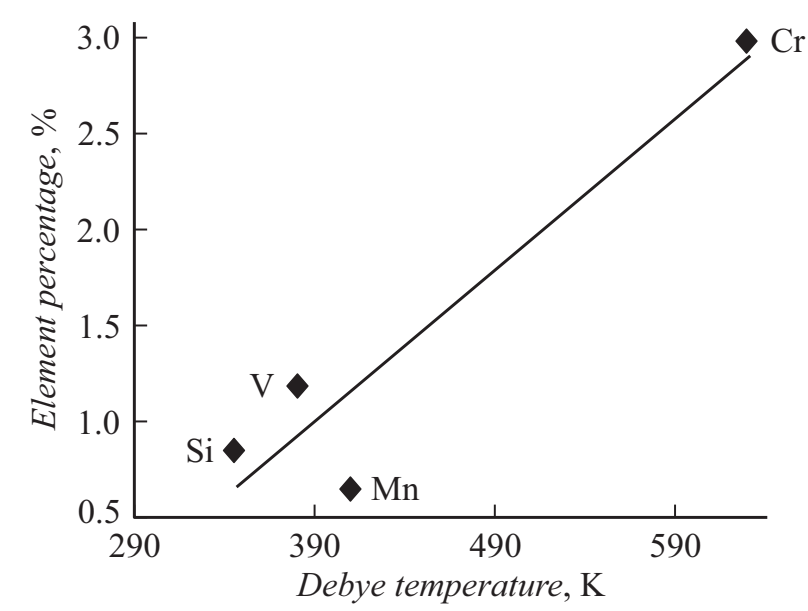

Рис. 6. Зависимость содержания элементов в междендритных объемах (\%) от температуры Дебая. Коэффициент корреляции 0.944.

тесно связаны с такой важной интегральной характеристикой твердого тела, как температура Дебая.

Например, значения эффективного атомного радиуса, растворенного в решетке компонента re, для $\mathrm{Ga}, \mathrm{Ge}$, As, Nb, Mo, Cd и In [1] оказались связанными с температурой Дебая химического элемента [2] (рис. 1).

Такое важное понятие, как интенсивность ликвации [2], также тесно связано с температурой Дебая (рис. 2).
Оценка дендритной ликвации в слитках электрошлакового переплава диаметром $100 \mathrm{~mm}$ для стали 05Х16Н4Д2Б [3] в функции температуры Дебая носит линейный характер (рис. 3).

Для элементов $\mathrm{Cr}, \mathrm{Si}, \mathrm{Cu}$ и $\mathrm{Ni}$ также прослеживается линейная зависимость коэффициента ликвации [3] от температуры Дебая $\Theta$. Коэффициент ликвации $=-0.3704+0.0024 \Theta$. Коэффициент корреляции 0.82 (рис. 4).

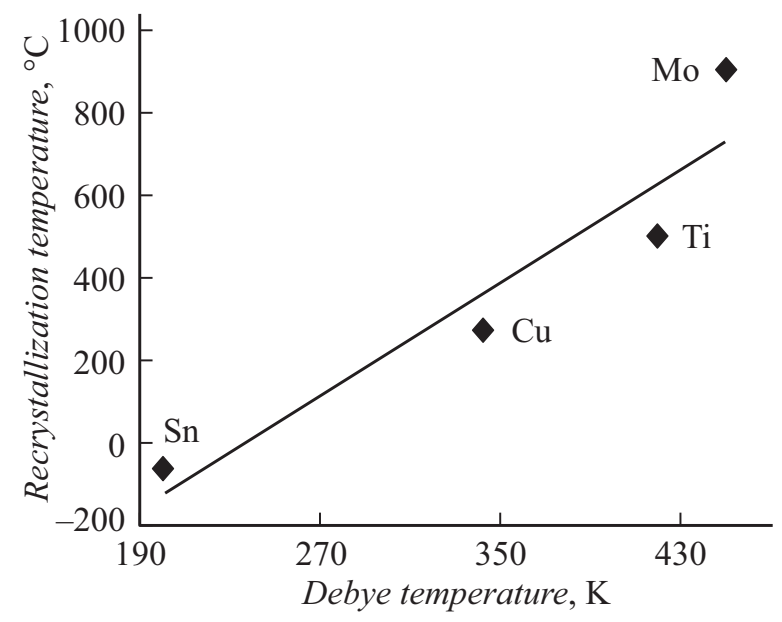

Рис. 7. Зависимость температуры рекристаллизации от температуры Дебая. Коэффициент корреляции 0.941.

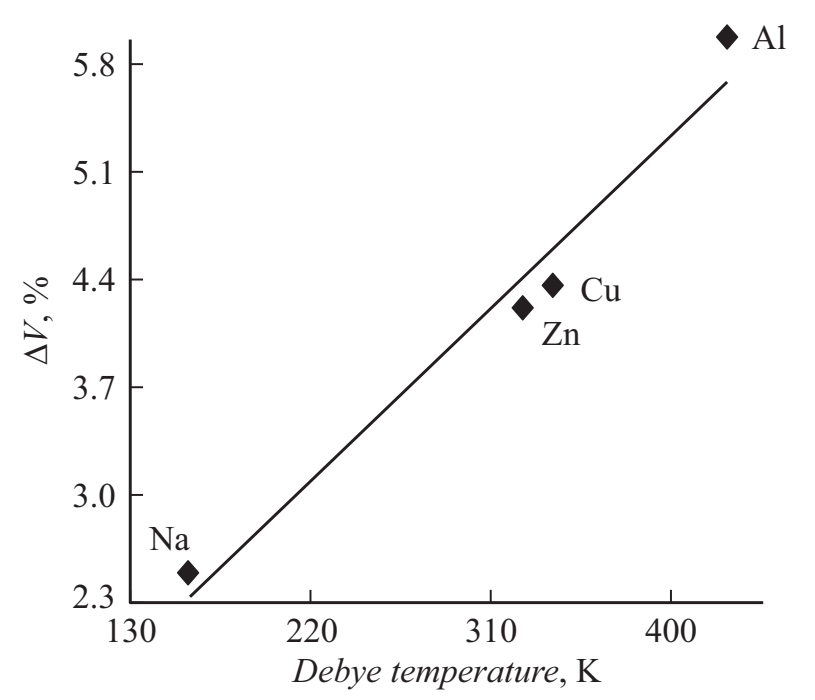

Рис. 8. Зависимость изменения объема $\Delta V$ от температуры Дебая. Коэффициент корреляции 0.978. 


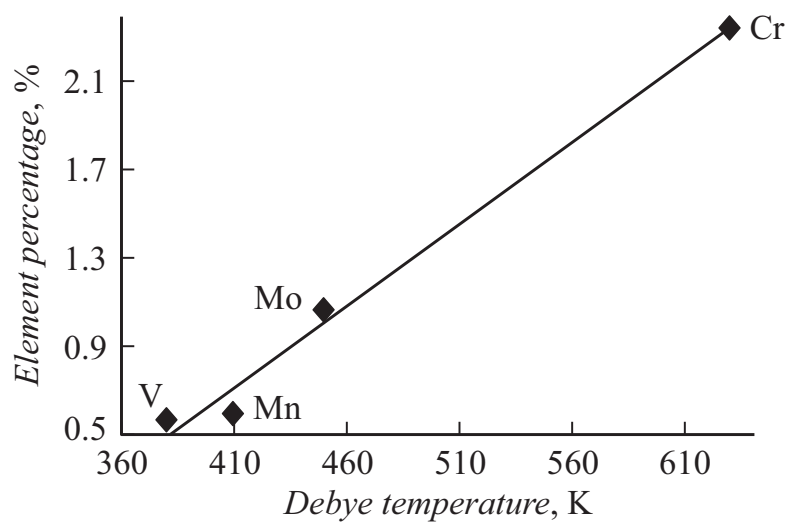

Рис. 9. Зависимость содержания элементов в осях дендритов (сталь 3Х2М2Ф в исходном литом состоянии) от температуры Дебая. Коэффициент корреляции 0.944.

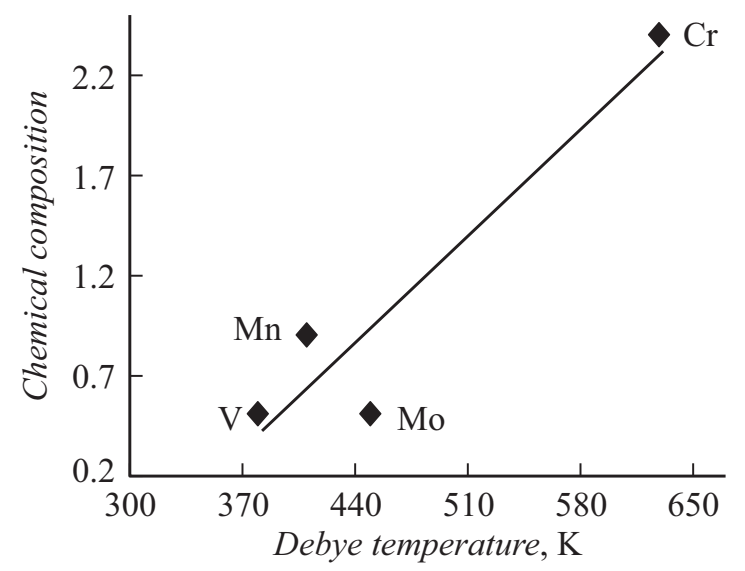

Рис. 10. Зависимость химического состава локальных областей от температуры Дебая. Коэффициент корреляции 0.941.

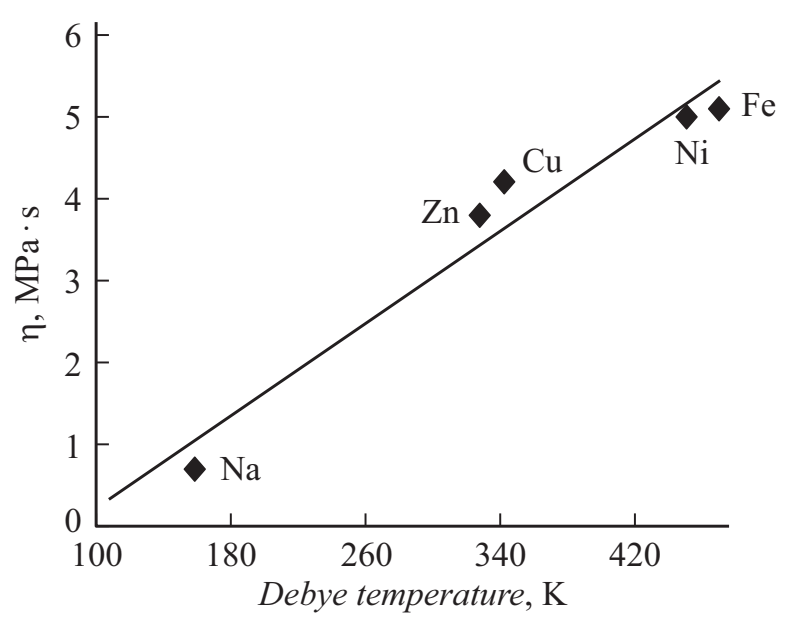

Рис. 11. Зависимость вязкости расплавленного металла $\eta$ от температуры Дебая. Коэффициент корреляции 0.972.

Интересно отметить связь максимального переохлаждения $\Delta T$, полученного методом малых капель [4], с температурой Дебая (рис. 5).
Следует отметить, что содержание элементов в структуре стали $3 \mathrm{X} 2 \mathrm{M} 2$ в исходном литом состоянии в междендритных объемах [1] также связано с температурой Дебая (рис. 6).

Температурные режимы обработки металлов также связаны с температурой Дебая. Например, температура рекристаллизации [5] для $\mathrm{Mo}, \mathrm{Ti}, \mathrm{Cu}$ и $\mathrm{Sn}$ зависит от температуры Дебая (рис. 7).

Процесс плавления связан с изменением объема $\Delta V$ (экспериментально найденные значения) [1]. На рис. 8 приведена зависимость изменений объема $\Delta V$ от температуры Дебая.

Повышенный интерес вызывает содержание элементов в осях дендритов в исходном литом состоянии [1]. На рис. 9 приведена зависимость содержания элементов в структуре стали $3 Х 2 \mathrm{M} 2 \Phi$ от температуры Дебая металла.

Распределение элементов в осях дендритов в междендритных микрообъемах в структуре штампованной стали 3Х2М2Ф не зависит от способа закалки (см. таблицу) [1].

Изменение химического состава локальных областей, которые выделяются в стали 26Х1МФА в процессе нагревания до температуры $810^{\circ} \mathrm{C}$, определенные с помощью микрорентгеноспектрального анализа [6] в функции температуры Дебая демонстрирует рис. 10.

Процесс ликвации в значительной степени определяется вязкостью расплавленного металла [1], которая в свою очередь связана с температурой Дебая (рис. 11).

Таким образом, процесс ликвации непосредственно связан с температурой Дебая металлического элемента.

\section{Список литературы}

[1] Ершов Г.С., Позняк Л.Ф. Микронеоднородность металлов и сплавов. М.: Металлургия, 1985. 214 с.

[2] Киттель Ч. Введение в физику твердого тела. М.: Наука, 1978. $791 \mathrm{c}$.

[3] Левков Л.Я. Теоретические предпосылки и практические методы управления физико-химическими и теплофизическими процессами при электрошлаковом переплаве, определяющие качество ответственных изделий. Диссертация докт. техн. наук. Москва, 2015.

[4] Вайнгард У. Введение в физику кристаллизации металлов. / Пер с англ. О.В. Абрамова. Под ред. Я.С. Уманского. М.: Мир, 1967. 170 с.

[5] Солнцев Ю.П., Пряхин Е.И. Материаловедение: Учебник для вузов. Изд. 4-е, перераб. и доп. СПб.: Химиздат, 2007. $784 \mathrm{c}$.

[6] Мусихин C.A. Влияние химической неоднородности среднеуглеродистых низколигированных сталей на формирование структуры и комплекса свойств при термическом воздействии. Диссертация канд. техн. наук. Екатериненбург, 2015. 